\title{
Oil refinery planning multi-projects under uncertainty
}

\author{
Gaibova Tatiana \\ Department of control and informatics in technical systems \\ Orenburg State University \\ Orenburg, Russian Federation \\ gaibovasau@mail.ru
}

\begin{abstract}
This article proposed multi-project thinking for planning of production of oil products, allowing one to take into account both complication of such projects and influence of uncertainty during their realization. The scenario planning and a model of choice under uncertainty are used. A procedure of payoff matrix formation is described concerning planning and making decision on the multi-projects of oil and gas industry. As alternatives, the scenarios of multi-project realization are examined with the different oil product portfolio. Every multiproject scenario is formed only on the basis of technological connections. In the long term, it is possible to form the scenarios with the opportunity to take into account the start of each individual project depending on investment possibilities and market situation.
\end{abstract}

As uncertain outcomes, the provision of a multi-project with oil resources is considered based on the projected rate of oil production at the well or field. It allows taking into account the uncertainty related to exhaustibility of the natural resource used.

As elements of a payoff matrix in the article, it is suggested to use indexes of commercial efficiency of investments. The questions of determining the dimension of the matrix and the selection of the planning horizon are discussed.

The results of application of the proposed approach to the multi-project of oil processing developed for the geological and economic conditions of the Orenburg region of the Russian Federation are described. The results indicate that reasonable solutions have been created. They are useful for determining the desired plans for the implementation of the project, the capital intensity of the created production and the risk of changes in the volume of oil production within the examined planning horizon.

Keywords-multi-project; planning; uncertainty; oil product portfolio

\section{INTRODUCTION}

The uncertainty affecting the implementation of the project has long been recognized by researchers as the main obstacle to making effective investment decisions. The problem is exacerbated when considering long-term and large-scale projects, as well as organizing production of an increased level of danger. Such projects include oil industry projects. Their main distinguishing feature is the use of exhaustible natural resources. The production of hydrocarbons is becoming increasingly difficult and expensive (hard-to-reach deposits, geographical remoteness from processing sites). Such projects are characterized by a high level of implementation risk. This is mainly due to the high capital intensity, the use of long- cycle equipment, the tightness of the pre-investment and investment phase of the project, the exhaustibility of the natural resource used. For the implementation of the project, construction and installation works take years. Often, the development of the project is carried out under the some conditions and its implementation is quite different.

Therefore, the solution of the problem of oil industry project planning requires a specific tool. This topic has been of interest to researchers for a long time and is widely discussed.

Discussions range from topics that take into account industry specificities such as planning oil refining production in [1], planning logistics of oil products in [2, 3] and capital investments in [4].

The world technological trend in the development of the oilfield business is the introduction of technologies for deep processing and complex use of oil. From the point of view of the organization of production, oil refining is a complex of functionally connected process units, which, depending on the depth of processing, produces a different set of petroleum products.

According to the principles of project management, the organization of oil refining should be considered as a multiproject with a product portfolio. Such multi-project consists of several technologically dependent projects united by a common group of goals.

Determination of the depth of processing forms a portfolio of petroleum products, the scope of work of the multi-project, the amount of necessary investment and the commercial effectiveness of each individual project and multi-project in general. The toolkit for managing multi-product multi-projects is discussed in [5-7].

In various researches devoted to project analysis, for example, in [8], it is indicated that the problem of risk and uncertainty is, to varying degrees, inherent in each project.

Sources of uncertainty, as well as approaches to mitigate it with a view to the successful completion of the project, are discussed in [9].

The specifics of accounting for uncertainty in the formation of product portfolios are set out in [10].

Although there are various typical instruments for managing uncertainty at the level of the overall project 
approach, as well as options for formulating a strategy in accordance with the characteristics of uncertainty; in practical application, they are faced with an overly generalized context of the project task.

So, for example, as a source of uncertainty of a project of any scale and any subject area, the authors are considering the situation on the market, the possible actions of competitors, the performance of the technologies being implemented.

The results of research of the actually used risk management tools presented in [11] show that all tools and methods of project management will be more effective if the formulation of project tasks is more clearly defined.

The purpose of this article is to propose an approach to planning and making investment decisions on the establishment of oil refining complexes, which allow one to reduce the uncertainty in the scope of work and the portfolio of petroleum products, taking into account the rate of exhaustibility of the natural resource.

\section{Methodology}

\section{A. Model of scenario planning of multiprojects for oil refining under uncertainty}

In determining the methodology for the problem being solved, the following reasoning was used.

The main method of project planning, allowing one to mitigate the influence of uncertainty, are multivariant calculations. They allow forming a set of project implementation scenarios to represent the consequences of the accepted project decisions.

UNIDO recommends the following areas for identifying project alternatives: the strategy and the framework of the project; market and marketing concept; raw materials, basic and auxiliary production materials; location, site and environment; planning and technology; organization and overhead; labor resources - labor costs and vocational training; project implementation schedule and budgeting.

Among these areas there are those that can be directly affected by the project decisions made and those that are influenced by the environment.

In the context of this article, two types of uncertainty can be identified: uncertainty in the project decisions made and uncertainty of the environment.

To take into account the uncertainties of both types, a classical model of choice under uncertainty is appropriate.

It illustrates the situation when with each alternative $\mathrm{x}$, a set of possible outcomes $\mathrm{Y}$ is related.

Which of the outcomes will be realized as a result of the choice of a concrete alternative at the time of the decision is unknown.

For the considered task of planning multi-projects of oil refining on the basis of multivariate calculations, it is expedient to use a discrete set of alternatives and outcomes.
The effectiveness of the use of multivariate calculations at the stage of making an investment decision is determined by the uniformity of coverage of the generated project alternatives by the generated scenarios.

At the same time, a complete search of all scenarios is not possible because of their large number and diversity both at the structural and parametric levels.

In the worst case, variant calculations allow us to assess the consequences of only individual decisions, but do not provide an overall picture of the project's possibilities.

Decision makers do not know if the most effective options have been left without consideration. At the same time, the illusion of qualitatively conducted planning is preserved.

To avoid such a situation, it is necessary to be aware of the structural rules that led to the generation of alternatives.

This will allow the decision-makers to know exactly what level of awareness they have in determining the project strategy.

The value of such reasoning becomes practically meaningful only when clarifying the context of the problem being solved - that is, when using information in the decisionmaking model about the features of the project's subject area and the conditions for the implementation project.

For the planning of oil refining multi-projects, based on the choice under uncertainty, the authors use a set of alternatives xi, $\mathrm{i}=1 \ldots \mathrm{N}$; a set of undefined outcomes $y \mathrm{j}, \mathrm{j}=1$ ... M; the resulting indicator qij for evaluating the results of the choice of the i-alternative and the realization of the $\mathrm{j}$ outcome.

As a separate alternative, it is suggested to consider the scenario of implementing the multi-project.

When forming each scenario, it is necessary to take into account the technological requirements that characterize the relationship between individual refining processes.

Table 1 shows the principle of forming a binary matrix of technological alternatives to a multi-project.

Elements of the matrix have two meanings: 1 - if the project is included in the scenario, 0 - if the project is not included in the scenario.

TABLE I. BINARY MATRIX OF TECHNOLOGICAL SCENARIOS

\begin{tabular}{|l|c|c|c|c|}
\hline \multirow{2}{*}{$\begin{array}{l}\text { Scenario of } \\
\text { multi-project }\end{array}$} & \multicolumn{4}{|c|}{ Projects as part of a multi-project } \\
\cline { 2 - 5 } & Project 1 & Project 2 & Project 3 & Project ... \\
\hline Scenario 1 & 1 & 1 & 0 & $\ldots$ \\
\hline Scenario 2 & 1 & 1 & 1 & $\ldots$ \\
\hline Scenario 3 & 1 & 0 & 0 & $\ldots$ \\
\hline$\ldots$ & $\ldots$ & $\ldots$ & $\ldots$ & $\ldots$ \\
\hline Scenario n & 1 & 0 & 0 & $\ldots$ \\
\hline
\end{tabular}

Technological requirements are the basis for determining the possibility of including a project in a particular scenario. 
Technological scenarios of the multi-project will have a different level refinery yield (expressed as a percentage) represents the percent of finished product produced from input of crude oil, hydrogen, other hydrocarbons, and net input of unfinished oils. It is calculated by dividing the sum of crude oil, hydrogen, other hydrocarbons, and net input of unfinished input into net production of each finished refinery product.

As the resultant indicator qij, the indicators of commercial efficiency of investments in the multiproject can be used to estimate the results of the choice of the i-alternative and the realization of the $\mathrm{j}$-outcome.

This study used the Profitability Index - PI, which is defined as follows:

$$
P I=\frac{\sum_{t=1}^{T} \frac{R(t)}{(1+q)^{t}}}{\sum_{t=0}^{m} \frac{K(t)}{(1+q)^{t}}}
$$

Equation (1) contains the following parameters: $\mathrm{T}$ planning horizon of the multi-project, $t$ - calculation step, $\mathrm{R}(\mathrm{t})$ - cash-flow of the t-step, $\mathrm{K}(\mathrm{t})$ - investment in the multiproject at the t-step, $\mathrm{m}$ - the last year of investments, $\mathrm{q}$ is the discount rate.

The general form of the payoff matrix for the problem under consideration is presented in Table 2.

TABLE II.

PAYOFF MATRIX OIL REFINERY PlanNING MULTIPROJECT

\begin{tabular}{|l|c|c|c|c|}
\hline \multirow{2}{*}{$\begin{array}{l}\text { Alternatives } \\
\text { actions }\end{array}$} & \multicolumn{4}{|c|}{ Stat of environment } \\
\cline { 2 - 5 } & $\boldsymbol{y}_{\boldsymbol{1}}$ & $\boldsymbol{y}_{2}$ & $\cdots$ & $\boldsymbol{y}_{\boldsymbol{m}}$ \\
\hline Scenario 1 & $\mathrm{PI}_{11}$ & $\mathrm{PI}_{12}$ & $\cdots$ & $\mathrm{PI}_{1 \mathrm{~m}}$ \\
\hline Scenario 2 & $\mathrm{PI}_{21}$ & $\mathrm{PI}_{22}$ & $\cdots$ & $\mathrm{PI}_{2 \mathrm{~m}}$ \\
\hline Scenario 3 & $\mathrm{PI}_{31}$ & $\mathrm{PI}_{32}$ & $\cdots$ & $\mathrm{PI}_{3 \mathrm{~m}}$ \\
\hline$\cdots$ & $\cdots$ & $\cdots$ & $\cdots$ & $\cdots$ \\
\hline Scenario n & $\mathrm{PI}_{\mathrm{n} 1}$ & $\mathrm{PI}_{\mathrm{n} 2}$ & $\cdots$ & $\mathrm{PI}_{\mathrm{nm}}$ \\
\hline
\end{tabular}

Presentation of the examined task as a payoff matrix allows one to consider disturbing effect from an environment and to distinguish the controlled uncertainty from out-ofcontrol.

As a state of the environment, the present research considers the sufficiency of resources oil for multi-project.

This is a multifactorial characteristic. This value is determined by the resource oil field potential, the annual level of oil production and the accumulated volume of oil production.

To make the projected values of available oil reserves comparable and the projected need for a multi-project, it is necessary to shift to relative values, measured in percent.

Since the scenario of the multi-project includes several projects with different levels of consumption of oil resources (both dark and with a certain degree of processing), then to form a single characteristic we will be forced to use the average value of sufficiency of resources.

At the stage of preliminary calculations for making an investment decision on a multi-project, we will consider this level of accuracy to be acceptable.

In the perspective, it is also possible to consider the possibility of maneuvering investment resources within a multiproject as ununcertain outcomes $\mathrm{y}_{\mathrm{j}}$,

This is possible for the following reasons.

Each project has different complexity, duration and capital intensity of preparatory works. The level of profitability of petroleum products is also very different.

Therefore, the start date of each project will directly affect the cash flow of the multiproject at each calculation step.

Capital costs in later projects can be offset from the profits of earlier projects. On the one hand, one should be guided by technological requirements for the interconnection of projects within the framework of a multiproject, and on the other hand, on investment opportunities and the availability of natural resources in the planning interval under consideration.

Accounting for the possibilities of maneuvering the investment resources of a multiproject is beyond the scope of this article.

That is, situations in which individual projects bring a sufficient level of profit and can be sent for investment in other projects have not been considered.

After conducting multivariate calculations and filling in the payoff matrix, one can use the traditional criteria maximin, minimax, Hurwicz optimism - pessimism criterion, Savage minimax regret criterion depending on the goal setting of the decision-maker.

\section{B. Discussion of the issues of determining the dimension of the payoff matrix and the planning horizon of the multi- project}

Determining the dimension of the payoff matrix directly affects the effectiveness of the proposed approach. The dimension of the matrix in question is determined by the number of technological scenarios of the multi-project and the number of uncertain outcomes associated with the exhaustibility of the oil resource on the source under consideration oil field.

In general, to determine the maximum number of possible technological combinations, it is possible to present the technological scheme of a multi-project of oil processing in the form of an oriented graph and use the breadth-first search method.

The number of uncertain outcomes of the multi-project's provision with oil resources depends on the stage of field development and the confidence interval of the predicted oil production figures. Consideration of more than 4-5 possible states at the stage of preliminary investment research will not, in the opinion of the author, lead to a significant improvement in the quality of decisions taken. 
The planning horizon for multi-project as a whole and for each project individually, directly affects the value of the resulting PI score. When determining it, it is necessary to take into account the service life of the main technological equipment, the period of development of design capacities and the payback period of the project.

\section{RESULTS}

To approbate the proposed approach, a multi-project of oil refining, developed for the conditions of the Orenburg region of the Russian Federation, was used. It consists of seven functionally connected separate technological installations, which allow producing seventeen kinds of oil products. The technological scheme of the multi-project under consideration is presented in Fig. 1.

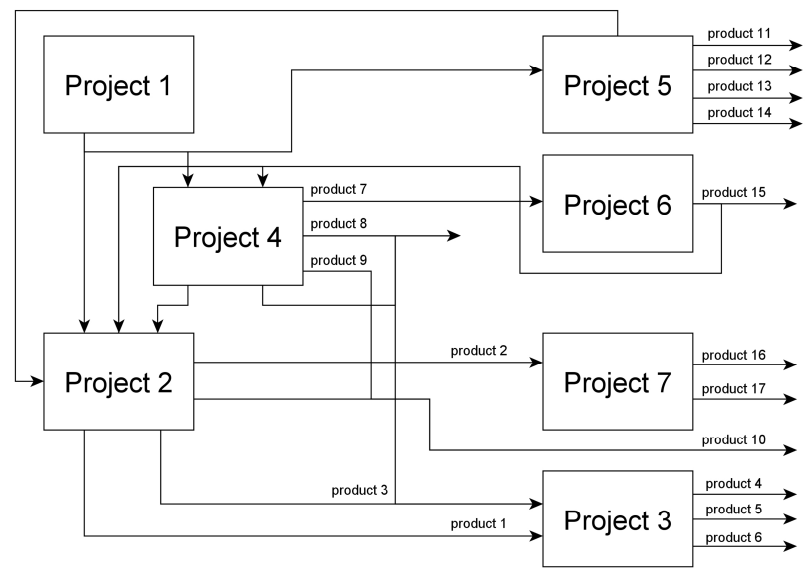

Fig. 1. A technological scheme of a multiproject of oil refining

It is necessary to determine the variants of the multiproject and to evaluate their effectiveness in the context influence of uncertainty.

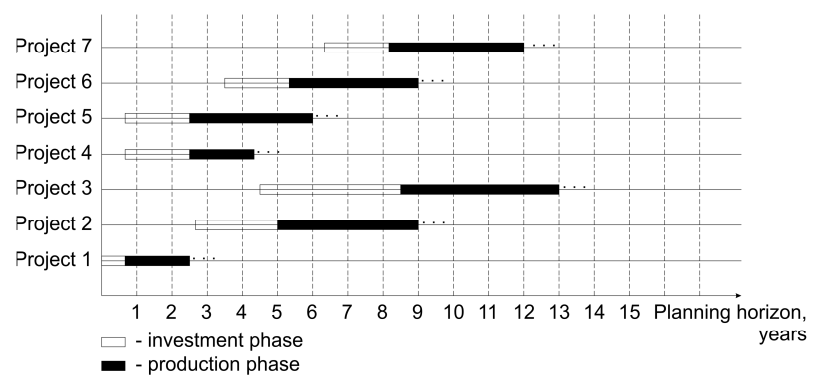

Fig.2.The Gantt chart of the multiproject under consideration

Fig. 2 shows the Gantt chart within the multiproject planning horizon.

In the formation of multiproject alternatives, only the depth of processing was varied. The sequence and start dates of each individual project were determined on the basis of technological requirements.
The basis for uncertain outcomes was chosen predicted rate of oil production in wells or oil fields - sources of resources, processed in the multiproject.

As a resultant indicator for carrying out multivariante calculations, the profitability index of the multi-project the Profitability Index PI was used.

When carrying out model calculations, fourteen variants of the multiproject were considered.

Each of these options includes various combinations of individual refinery technological projects and a corresponding portfolio of petroleum products.

The product portfolio of each multiproject scenario is presented in Table 3.

TABLE III.

PRODUCT PORTFOLIO OF SCENARIOS OF MULTI-PROJECT

\begin{tabular}{|l|l|l|}
\hline $\begin{array}{l}\text { Scenario } \\
\text { of } \\
\text { multiproject }\end{array}$ & $\begin{array}{l}\text { Projects of } \\
\text { scenario }\end{array}$ & Product portfolio of scenario \\
\hline 1 & 1,2 & $1,2,3,10$ \\
\hline 2 & $1,2,3$ & $1,2,3,4,5,6,10$ \\
\hline 3 & $1,2,4$ & $1,2,3,7,8,9,10$ \\
\hline 4 & $1,2,7$ & $1,2,310,16,17$ \\
\hline 5 & $1,2,5$ & $1,2,3,10-14$ \\
\hline 6 & $1,2,3,7$ & $1,2,3,4,5,6,10,16,17$ \\
\hline 7 & $1,2,4,5$ & $1,2,3,7,8,9,10,11,12,13,14$ \\
\hline 8 & $1,2,4,6$ & $1,2,3,7-10,15$ \\
\hline 9 & 1,4 & $7,8,9$ \\
\hline 10 & $1,4,5$ & $7,8,9,11-14$ \\
\hline 11 & $1,4,6$ & $7,8,9,15$ \\
\hline 12 & 1,5 & $11-14$ \\
\hline 13 & $1,4,5,6$ & $7,8,9,11-15$ \\
\hline 14 & $1-7$ & $1-17$ \\
\hline
\end{tabular}

An example of the technological scheme of the sixth variant is shown in Fig. 3.

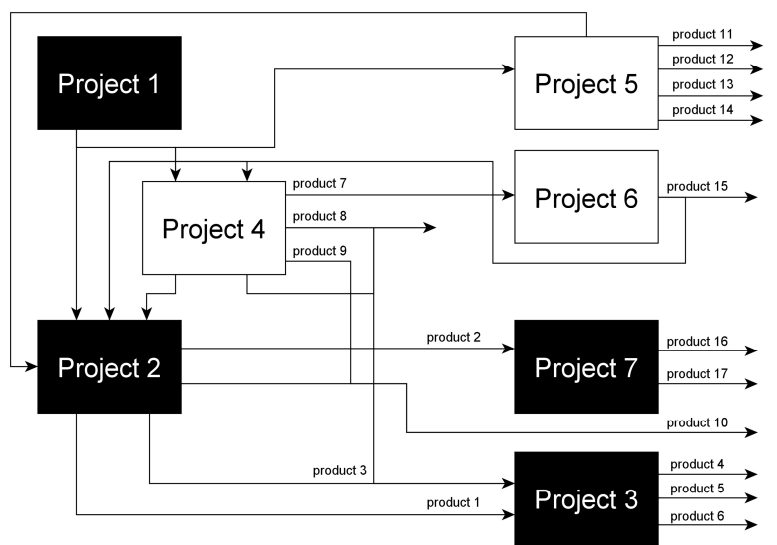

Fig.3.A technological scheme of the sixth scenario of the multiproject

Based on the technological scheme, the amount of work for each individual project was determined and the projected cash flows were modeled.

Modeling was carried out for the highest possible level of production for the selected type of process equipment and the projected oil production volume assumed as the base one. 
The resulting matrix is shown in Table 4.

TABLE IV.

The PAyoff Matrix Of The Test Multi-Project

\begin{tabular}{|c|c|c|c|c|}
\hline \multirow{2}{*}{ Scenarios } & \multicolumn{4}{|c|}{ Sufficiency of oil resources for the multi-project } \\
\cline { 2 - 5 } & $\mathbf{1 0 0} \%$ & $\mathbf{8 0 \%}$ & $\mathbf{6 0 \%}$ & $\mathbf{4 0 \%}$ \\
\hline 1 & 1.32 & 1.28 & 1.16 & 1.04 \\
\hline 2 & 1.36 & 1.26 & 1.11 & 0.68 \\
\hline 3 & 1.27 & 1.12 & 1.04 & 0.72 \\
\hline 4 & 1.28 & 1.14 & 1.08 & 0.84 \\
\hline 5 & 1.38 & 1.19 & 1.05 & 0.76 \\
\hline 6 & 1.65 & 1.56 & 1.11 & 0.94 \\
\hline 7 & 1.40 & 1.33 & 1.12 & 1.04 \\
\hline 8 & 1.62 & 1.43 & 1.06 & 0.82 \\
\hline 9 & 1.34 & 1.18 & 1.02 & 0.62 \\
\hline 10 & 1.12 & 1.07 & 1.01 & 0.89 \\
\hline 11 & 1.26 & 1.18 & 1.09 & 0.83 \\
\hline 12 & 1.37 & 1.22 & 1.12 & 0.86 \\
\hline 13 & 1.41 & 1.29 & 1.16 & 1.03 \\
\hline 14 & 1.47 & 1.31 & 1.03 & 0.87 \\
\hline
\end{tabular}

\section{CONCLUSION}

In this article, the principles of multivariant planning of oil refining multi-projects under uncertainty are considered. As alternatives in the payoff matrix, the authors formed the scenarios for the implementation of the multi-project, taking into account technological requirements.

As uncertain outcomes, the sufficiency of oil resources for the multi-project was chosen. An example of the application of a planning model for a multi-project of oil refining consisting of seven interrelated projects is given.
The proposed approach allows formulating solutions for the planned oil products portfolio, the scope of work at each step of the multi-project, taking into account the exhaustibility of the natural resource used.

\section{References}

[1] M. Joly, "Refinery production planning and scheduling: the refining core business," Brazilian Journal of Chemical Engineering, vol. 29(02), pp. 371-384, 2012.

[2] P.K. Dey, M.T. Tabucanon, S. Ogunlana, "Hierarchical approach to project planning: The case of a petroleum pipeline construction," Applied Mathematical Modelling, vol 20, pp.683-698, September 1996.

[3] S.A. Mirhassani, "An operational planning model for petroleum products logistics under uncertainty," Applied Mathematics and Computation, vol. 196(2), pp.744-751, March 2008.

[4] B.C. Menezes, J.D. Kelly, I.E. Grossman, A. Vazacopoulos, "Generalized capital investment planning of oil-refineries using MILP and sequence-dependent setups," Computers \& Chemical Engineering, vol.80, pp.140-154, September 2015.

[5] D. Jugend, S.L.da Silva, "Product portfolio management: a framework based on methods, organisation and strategy," Concurr. Eng. Res. Appl. , vol. 22 (1), pp. 17-28, 2014.

[6] A. Platje, H. Seidel, S. Wadman, "Project and portfolio planning cycle: Project-based management for the multiproject challenge," International Journal of Project Management, 12(2), pp.100-106, 1994.

[7] U. Beşikci, U. Bilge, G. Ulusoy, "Multi-mode resource constrained multi-project scheduling and resource portfolio problem," European Journal of Operational Research, vol. 240(1), pp. 22-31, January 2015.

[8] O. Perminova, M. Gustafsson, K. Wikström, "Defining uncertainty in projects-a new perspective," International Journal of Project Management, vol. 26, pp. 73-79, 2008.

[9] F.C. Saunders, A.W. Gale, A.H. Sherry, "Conceptualising uncertainty in safety-critical projects: A practitioner perspective," International Journal of Project Management, vol. 33, pp. 467-478, 2015.

[10] J. Oh, J. Yang and S. Lee, "Managing uncertainty to improve decisionmaking in NPD portfolio management with a fuzzy expert system," Expert Systems with Application, vol. 39(10), pp. 9868-9885, 2012.

[11] C. Besner, B. Hobbs, "The paradox of risk management; a project management practice perspective", International Journal of Managing Projects in Business, Vol. 5(2), pp.230-247, 2012. 